\title{
Colonization of Dormant Walnut Buds by Xanthomonas arboricola pv. juglandis Is Predictive of Subsequent Disease
}

\author{
Steven Lindow, William Olson, and Richard Buchner
}

First author: Department of Plant and Microbial Biology, University of California, Berkeley 94720; second author: University of California Cooperative Extension, Oroville; and third author: University of California, Cooperative Extension, Red Bluff. Accepted for publication 23 April 2014

\section{ABSTRACT}

Lindow, S., Olson, W., and Buckner, R. 2014. Colonization of dormant walnut buds by Xanthomonas arboricola pv. juglandis is predictive of subsequent disease. Phytopathology 104:1163-1174.

The potential role of walnut buds as a driver of walnut blight disease, caused by Xanthomonas arboricola pv. juglandis, was addressed by quantifying its temporal dynamics in a large number of orchards in California. The abundance of $X$. arboricola pv. juglandis on individual dormant and developing buds and shoots of walnut trees varied by $>10^{6}$ fold at any sample time and within a given tree. $X$. arboricola pv. juglandis population size in shoots was often no larger than that in the buds from which the shoots were derived but was strongly correlated with prior pathogen population sizes in buds. X. arboricola pv. juglandis populations on developing nuts were strongly related to that on the shoots on which they were borne. The incidence of disease of nuts in June was strongly correlated with the logarithm of the population size of $X$. arboricola pv. juglandis in dormant buds in March. Inoculum efficiency, the slope of this linear relationship, varied between years but was strongly related to the number of rain events following bud break in each year. Thus, inoculum of $X$. arboricola pv. juglandis present on dormant buds is the primary determinant of nut infections and the risk of disease can be predicted from both the numbers of $X$. arboricola pv. juglandis in buds and the incidence of early spring rain.
Bacterial blight of Persian (English) walnut (Juglans regia L.) caused by Xanthomonas arboricola pv. juglandis is the most serious aboveground disease of walnut in California and a major disease of this crop in nearly all parts of the world in which it is grown $(12,18,21)$. Although the pathogen can attack flowers, shoots, leaves, and buds, nuts are generally most susceptible. Most economic loss due to walnut blight disease is associated with nut infections. Infections of nuts can lead to very high incidences of premature fruit drop, and yield of nuts on trees is directly related to the incidence of infection $(5,12,19,21)$. In addition, infected nuts that remain on the tree can exhibit staining of the shell which can reduce the quality of nuts sold in-shell. Although there has been considerable effort made to identify those walnut genotypes most highly resistant to $X$. arboricola pv. juglandis infection $(2,6,12,26,28)$, all commercially grown walnut varieties are considered susceptible to walnut blight disease.

Management strategies for walnut blight aim to protect susceptible nuts by application of copper-based biocides at regular intervals after bud break. Conventional programs of disease control by such a strategy can require five or more applications per year, depending on prevailing weather conditions $(3,4,12,19,20)$. Frequent applications of copper compounds to walnut trees has selected for resistant strains of $X$. arboricola pv. juglandis, greatly reducing the efficacy of such compounds for disease control unless used in combination with compounds such as ethylene bisdithiocarbamate fungicides $(3,4,20)$. Because of the cost and regulatory restrictions on the use of such protective materials due to their environmental impact, there is a need to better understand the processes that contribute to infection of walnut tissue by

Corresponding author: S. Lindow; E-mail address: icelab@berkeley.edu

* The $\boldsymbol{e}$-Xtra logo stands for "electronic extra" and indicates that the online version contains four supplemental figures.

http://dx.doi.org/10.1094/PHYTO-01-14-0001-R

(C) 2014 The American Phytopathological Society
$X$. arboricola pv. juglandis so that the use of these materials can be minimized. Unfortunately, relatively little is known about epidemiological processes that lead to infection by $X$. arboricola pv. juglandis. Earlier work had demonstrated that the pathogen could be isolated from overwintering cankers on trees $(18,20,21)$. $X$. arboricola pv. juglandis could also be found on pollen released from trees exhibiting walnut blight symptoms (18). Subsequent work, however, suggested that cankers and pollen were not important sources of initial inoculum for the pathogen in a given growing season, and circumstantial evidence suggested that the inoculum present in healthy dormant buds was sufficient to account for infection (18). For example, the incidence of colonization of such buds was higher in that portion of the trees subject to sprinkler irrigation and which had a higher incidence of disease than in upper parts of the same trees (18). Likewise, application of copper hydroxide-based bactericides to dormant trees reduced both the incidence of bud infestation by $X$. arboricola pv. juglandis as well as subsequent disease (18). The incidence of $X$. arboricola pv. juglandis colonization of buds that developed on shoots harboring symptomatic leaves was also higher than that on shoots having only healthy leaves (18), suggesting that subsequent epidemics could be driven by inoculum from such buds.

Although an epidemiological model in which buds serve as initial inoculum for epidemics initiated each spring is supported by these earlier reports on the presence of $X$. arboricola pv. juglandis in walnut buds, more detailed information on spatial and temporal variation of pathogen abundance in trees is needed to better link such sources with subsequent infection. For example, although buds may serve as sources of initial inoculum, it will be important to know the extent to which such inoculum initiates local infection of nuts derived from a given bud, or whether such inoculum can lead to infection of nuts elsewhere on a tree. Because earlier work had suggested that not all buds in a tree harbor inoculum of $X$. arboricola pv. juglandis (18), it seemed possible that the first scenario, in which inoculum in buds primarily drove infection of nearby susceptible tissues, would be 
operative. In such a scenario, the likelihood of disease might be predictable based on the incidence of infestation of asymptomatic dormant buds. In this study, we performed detailed analysis of the spatial and temporal variation of $X$. arboricola pv. juglandis populations in various walnut tissues throughout the growing season in orchards differing in the amount of disease that they suffered to better understand the sources of inoculum and process of infection. We show that $X$. arboricola pv. juglandis is highly spatially segregated in walnut trees throughout the growing season and that inoculum in dormant buds is the primary determinant of the likelihood of infection of nuts that form on shoots derived from such buds. Furthermore, we show that the incidence of walnut blight disease in a given orchard can be predicted from both the proportion of buds which harbor $X$. arboricola pv. juglandis and also the frequency with which rainfall occurs soon after bud break.

\section{MATERIALS AND METHODS}

Field plot design. All sampling was made from untreated trees of various walnut cultivars grown in commercial orchards in northern and central California. The most intensive sampling from 1994 through 1999 was performed on 'Ashley' walnut grown in orchard A located near Red Bluff, CA as well as orchard B located near Oroville, CA. Repeated sampling was also made of different cultivars in 12 additional orchards located within a radius of $30 \mathrm{~km}$ of Red Bluff and Oroville, CA in 1995 and subsequent years. Orchards 2 to 5, 7 to 9, 11, and 12 were planted to Ashley, while orchards 1 and 10 contained 'Vina' and orchard 6 contained 'Serr'. In some years after 1999, trees untreated with bactericides in additional commercial orchards in the Sacramento Valley and Northern San Joaquin Valley of California were sampled. Ashley and Vina were grown in most of these additional orchards. These cultivars are relatively early leafing varieties which historically suffer from the highest incidence of walnut blight disease, likely because their early date of bud opening maximizes the opportunity for green tissues to experience rainfall events that decline in frequency after approximately April 1 due to the Mediterranean climate in California. However, some orchards $(<20 \%)$ planted to 'Hartley' and 'Chandler' were also sampled. All orchards consisted of relatively mature trees (10 to 30 years old) that had received fertilizer, insecticide, and other pesticide applications consistent with good management practices for walnut in California but were not treated with any bactericides for the control of walnut blight disease. Although other portions of these orchards sometimes were subject to bactericide applications, such treatments were omitted on a minimum of those 10 trees in each orchard that were sampled periodically during the year in this study. The meteorological conditions experienced at each sampling site were determined by interrogation of parameters recorded for the closest California Irrigation Management Information System weather station (http://www.cimis.water. ca.gov ), usually located within $10 \mathrm{~km}$ of a given orchard. The incidence of rainfall events between late March (the date of bud opening for the earliest varieties in the study) and 1 June were determined for each orchard sampled in a given year.

Quantification of $X$. arboricola pv. juglandis on walnut tissues. The population size of $X$. arboricola pv. juglandis on a given plant part was determined by plating of appropriate dilutions of macerated tissue on Tween medium B (TWB) medium (16) containing natamycin at $50 \mu \mathrm{g} / \mathrm{ml}$ to inhibit fungal growth. $X$. arboricola pv. juglandis formed very distinctive characteristic small, light-yellow colonies surrounded by a zone of bright white crystals formed by the calcium salts of fatty acids released from Tween 80 by the lipolytic enzymes of $X$. arboricola pv. juglandis. Due to the selective nature of TWB, few other yellow colonies were detected on dilution plates from walnut tissues, and very few of these other yellow colonies produce a white halo. Nearly all other yellow colonies also were much larger and flatter than the small, dome-shaped colonies formed by $X$. arboricola pv. juglandis. Slow-growing bacteria that formed pale yellow colonies on King's medium B (11) in similar numbers as those producing characteristic small yellow colonies with a white halo on TWB were observed when macerated bud tissues from a given sample were dilution plated on these two media. Thus, the apparent plating efficiency of $X$. arboricola pv. juglandis on TWB was quite high, like that of many other pathovars of $X$. campestris tested previously (16). In total, 300 colonies representatives of putative $X$. arboricola pv. juglandis strains were randomly chosen from samples from 15 different orchards for further characterization. All putative $X$. arboricola pv. juglandis cultures exhibited abundant growth on quinate-containing media, a characteristic of $X$. arboricola pv. juglandis that is uncommon among other Xanthomonas spp. (13). Each of 22 quinate-tolerant strains exhibiting the characteristic colony morphology of $X$. arboricola pv. juglandis on TWB media also incited typical walnut blight lesions when spray inoculated onto immature nuts of Hartley, Vina, Chandler, and 'Chico' walnut grown at the Kearney Agricultural Research and Extension Center, located at Parlier, CA. Thus, walnut tissues appear to harbor few cells of other Xanthomonas spp. that might also be recovered on TWB, and this medium appears highly selective for X. arboricola pv. juglandis, with its highly distinctive colonies that easily distinguish it from other taxa.

The population size of $X$. arboricola pv. juglandis was determined in each of several different tissue types associated with dormant and vegetatively growing walnut trees. Prior to the emergence of green tissues on trees in the spring, terminal branchlets $(\approx 20 \mathrm{~cm}$ in length, 25 per orchard) containing large terminal buds likely to give rise to flower-containing shoots were excised from random locations throughout trees at each orchard at a height of 2 to $4 \mathrm{~m}$ above the soil. A single terminal bud was excised from each sampled branchlet with a sterile razor blade and macerated in a sterile mortar and pestle with a minimal volume of sterile water $(2 \mathrm{ml})$. X. arboricola pv. juglandis population sizes were then estimated by plating of appropriate dilutions of bud macerate on TWB as above. When green tissues were present on trees, entire individual developing shoots were excised from each branch and placed separately within a sterile paper bag enclosed within a plastic bag to prevent drying, and transported to the laboratory for analysis. In most studies, the distinct developmental stages present on the shoot were separately excised and $X$. arboricola pv. juglandis populations were measured. When shoots had developed sufficiently to harbor immature nuts ( $\approx 2$ weeks after the initiation of bud opening), the nuts harbored on a given shoot (from 1 to 4 nuts per shoot) were excised and pooled before the remaining shoot tissue as well as the excised nuts were separately macerated and dilution plated to enumerate $X$. arboricola pv. juglandis population sizes. Immature shoots (less than $\approx 10 \mathrm{~cm}$ in length) were macerated in a sterile mortar and pestle containing $10 \mathrm{ml}$ of sterile water. Larger, more mature shoots were macerated in a food blender with as much as $200 \mathrm{ml}$ of sterile water. Nuts were macerated in a food blender with $50 \mathrm{ml}$ of sterile water. In some studies of orchards A and B, small, immature buds that formed on the axis of the newly developing shoots in a given spring, and which would overwinter and give rise to new shoots the following spring, were excised with a sterile razor blade and macerated in a mortar and pestle containing $1 \mathrm{ml}$ of sterile water and appropriate dilutions plated on TWB.

Semidestructive sampling of individual dormant walnut buds (100 per orchard) was also conducted in some orchards. A sterile scalpel was used to gently excise part $(\approx 50 \%)$ of the outer bud scale and outermost cataphyll present on individual terminal buds of Ashley walnut trees in early March, shortly before bud break in late March. The bud scales and cataphylls excised from a given 
bud were collected, returned to the laboratory on ice, macerated in a mortar and pestle with a small volume $(1 \mathrm{ml})$ of sterile water, and dilution plated on TWB as above. A small plastic tie was placed around the branchlet close to the sampled bud to enable a linkage to be made between population size of $X$. arboricola pv. juglandis on that bud and the presence or absence of disease on nuts that would subsequently develop on shoots emerging from the residual bud tissues. Nearly all sampled buds gave rise to shoots soon after sampling.

Assessment of disease incidence. The incidence of walnut blight disease was assessed by visual inspection of at least 400 individual nuts on each of four trees in a given orchard. Disease assessment was performed in early June of each year. Although disease typically increases from late April until 1 June in each year $(3,20)$, little additional increase in disease incidence occurs after 1 June. Furthermore, infected nuts seldom excise from trees before approximately 1 June but increasing incidence of drop of both healthy and disease nuts occurs after this time. For that reason, the most representative assessment of disease incidence on nuts was made in late May or early June. The presence of disease on at least 100 nuts was assessed in each of four quadrants of a given tree within a band from $\approx 2$ to $4 \mathrm{~m}$ above the soil. All nuts within discrete, 1.5-m-diameter, randomly chosen locations within the canopy of a given walnut tree were visually inspected for the presence of dark, discolored lesions typical of walnut blight disease, typically occurring on the distal, flower end of the nut but occasionally located laterally around the equator of the nut. The simple presence or absence of disease for each nut was recorded. Similarly, the presence or absence of disease for each nut which was borne on a shoot arising from a given bud which had been semidestructively sampled for the presence of $X$. arboricola pv. juglandis was recorded.

Statistical analysis. Variance of all data was assessed using Statistica 9 software (Statsoft, Tulsa, OK). Normality of estimated $X$. arboricola pv. juglandis population sizes in a given plant organ was determined using a Shapiro-Wilk test. Normality was achieved for most samples after log transformation. A value of $1.0\left(\log _{10}=\right.$ 0) (which was close to the detection limit for many samples) was assigned to censored data for samples in which $X$. arboricola pv. juglandis was not detected (7). The normality of log-transformed population sizes was visualized in plots of cumulative probability of observations against log-transformed population sizes. The proportion of population sizes greater than a given threshold size was also estimated from extrapolation from the cumulative probability plots. Linear regression between various dependent and independent variables was also conducted using Statistica 9.

\section{RESULTS}

Population size of $X$. arboricola pv. juglandis on different walnut tissues varies over time. The population dynamics of $X$. arboricola pv. juglandis in walnut trees was assessed on buds, developing shoots, and nuts over a period of several months on untreated Ashley walnut trees in two commercial orchards in northern California. Total pathogen population size was assessed by macerating tissues; therefore, surface and internal populations were not distinguished. The population size of $X$. arboricola pv. juglandis on a given plant part was quite temporally dynamic. In both orchards, the population sizes of $X$. arboricola pv. juglandis on new buds (which formed in April of each year on newly developing shoots) generally increased during the warm, dry summer months. In most years, the maximum $X$. arboricola pv. juglandis population size on buds occurred approximately December. Population sizes of $X$. arboricola pv. juglandis on buds were usually twofold or more lower in late winter, immediately before bud opening (Fig. 1). At both locations, X. arboricola pv. juglandis population sizes generally decreased in buds between spring 1994 and summer 1996 (Fig. 1), although population sizes increased somewhat in subsequent years at site A (Fig. 1A). Bud populations remained $>10^{3}$ cells/bud during 1999 before decreasing to $\approx 10$ cells/bud in 2000 and 2001 and then increasing to $\approx 10^{3}$ cells/bud by 2002 (data not shown). The population size of $X$. arboricola pv. juglandis was often nearly as high as or higher in unopened buds as in any other plant part at a given sampling time. For example, at site A, the population size of $X$. arboricola pv. juglandis on buds was $\approx 5 \times 10^{5}$ cells/bud $\left(\approx 10^{6} / \mathrm{g}\right)$ upon opening in 1995 whereas its maximum population size on shoots was generally $<10^{6}$ cells/shoot $\left(<10^{5} / \mathrm{g}\right)$ throughout the 1995 growing season, and tended to decrease with time (Fig. 1A). It should be noted that the mass of developing buds was 10- to 100-fold less than that of the shoots to which they gave rise. A similar temporal dynamics of $X$. arboricola pv. juglandis populations was observed at site $\mathrm{B}$, although lower numbers of cells were generally recovered at a given time. Whereas population sizes of $X$. arboricola pv. juglandis on buds when they opened at this site was $\approx 10^{4}$ cells/bud in 1995 , fewer than $\approx 10^{5}$ cells per shoot were subsequently recovered, and shoot populations tended to decrease with time during the growing season (Fig. 1B). The much lower population sizes of $X$. arboricola pv. juglandis on unopened buds
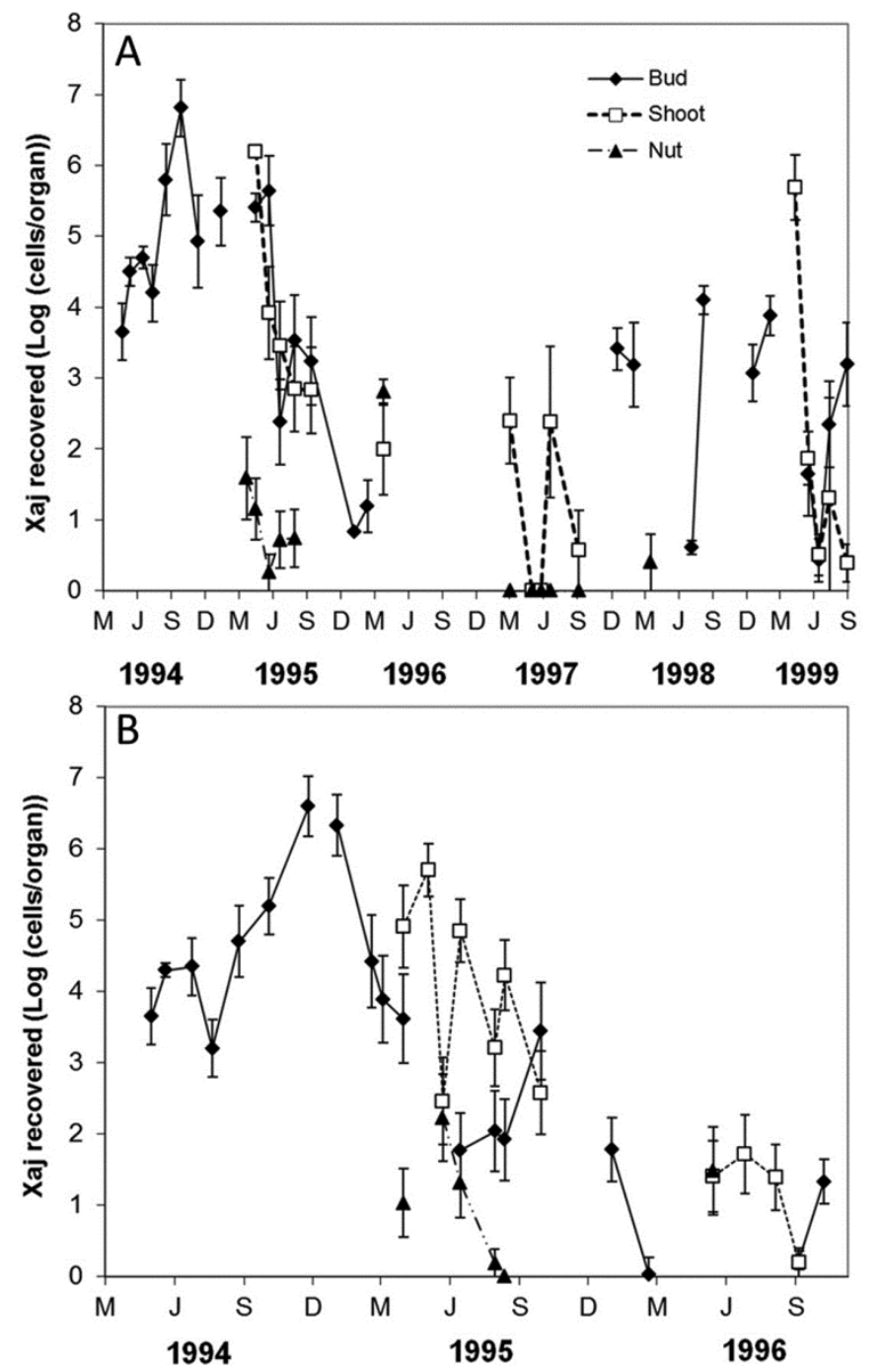

Fig. 1. Population sizes of Xanthomonas arboricola pv. juglandis on dormant and developing buds (squares), shoots on which developing nuts had been excised (circles), and developing nuts (triangles) on untreated Ashley walnut trees in a commercial orchard $\mathbf{A}$, in site $\mathbf{A}$ or $\mathbf{B}$, in site $\mathrm{B}$ in northern California. Months: $\mathrm{M}=$ March, $\mathrm{J}=$ June, $\mathrm{S}=$ September, and $\mathrm{D}=$ December. Vertical bars represent the standard error of the determination of mean logtransformed population sizes for 10 replicate samples of each organ sampled. 
in March 1996 were associated with correspondingly lower population sizes on developing shoots in that year at both sites (Fig. 1). Although relatively large population sizes of $X$. arboricola pv. juglandis ( $>10^{4}$ cells/organ) were found on shoots and buds that developed on those shoots during spring and summer 1995, the population sizes recovered from nuts on trees of both sites were usually $>100$-fold less (Fig. 1). The population size of $X$. arboricola pv. juglandis on developing nuts was always $>100$-fold lower than that on the shoots on which they were born (Fig. 1). For example, although average population size of $X$. arboricola pv. juglandis on shoots during the early summer 1995 at site B ranged from $10^{3}$ to $10^{4}$ cells/ shoot, less than $\approx 10$ cells/nut were recovered on average (Fig. 1A). Similarly low population sizes on nuts were seen in subsequent years as well (Fig. 1A). Likewise, although average population sizes of $X$. arboricola pv. juglandis on shoots during early summer 1995 at site A were $\approx 10^{4}$ and $10^{5}$ cells/shoot, fewer than $\approx 100$ cells were recovered per nut (Fig. 1B). We considered that $X$. arboricola pv. juglandis population sizes on nuts might have been underestimated due to the presence of inhibitory compounds released during maceration. To test this hypothesis, we added cultured cells of $X$. arboricola $\mathrm{pv}$. juglandis to macerated nuts harvested in May of each year; similar numbers of viable cells were recovered from such spiked macerates as from buffer alone, indicating that maceration of nut tissue does not prevent recovery of viable $X$. arboricola pv. juglandis.

We further tested the hypothesis that inoculum is transferred from buds to developing shoots by comparing the relative population sizes on these two organs in several other orchards in 1996.
Generally, total $X$. arboricola pv. juglandis population sizes in buds were similar to the maximum population sizes observed on shoots that developed within $\approx 14$ days of bud opening in a given orchard (Fig. 2). In addition, the maximum population sizes on shoots within $\approx 30$ days of bud break in a given orchard was generally proportional to that on buds before they opened (Fig. 2). For example, the population sizes of $X$. arboricola pv. juglandis on both buds and shoots were $\approx 10^{3}$ cells in orchard 3 whereas they were both only $\approx 10$ cells in orchard 2 (Fig. 2C). The relatively low population sizes of $X$. arboricola pv. juglandis seen in both buds and shoots in the several additional orchards that were sampled in 1996 (generally $<10^{4}$ cells/organ) reflected the lower pathogen population sizes measured in the more intensively sampled orchards A and B (Fig. 1).

The process of colonization of developing walnut buds by $X$. arboricola pv. juglandis was further investigated by analyzing its distribution of population sizes on large numbers of individual buds collected at different times during the summer months at two orchard sites. The population size of $X$. arboricola pv. juglandis in a given bud varied greatly within an orchard at a particular sampling time. For example, population sizes on developing buds collected on 25 May at both orchards $A$ and $B$ varied from $\approx 100$ cells/bud to nearly $10^{6}$ cells/bud (Fig. 3). Bud populations on this date could be described by a log-normal distribution because a nearly linear relationship was seen when the cumulative normal score was plotted as a function of log-transformed population size per bud (Fig. 3). In each orchard, the X. arboricola pv. juglandis populations on individual buds sampled again on 17 June
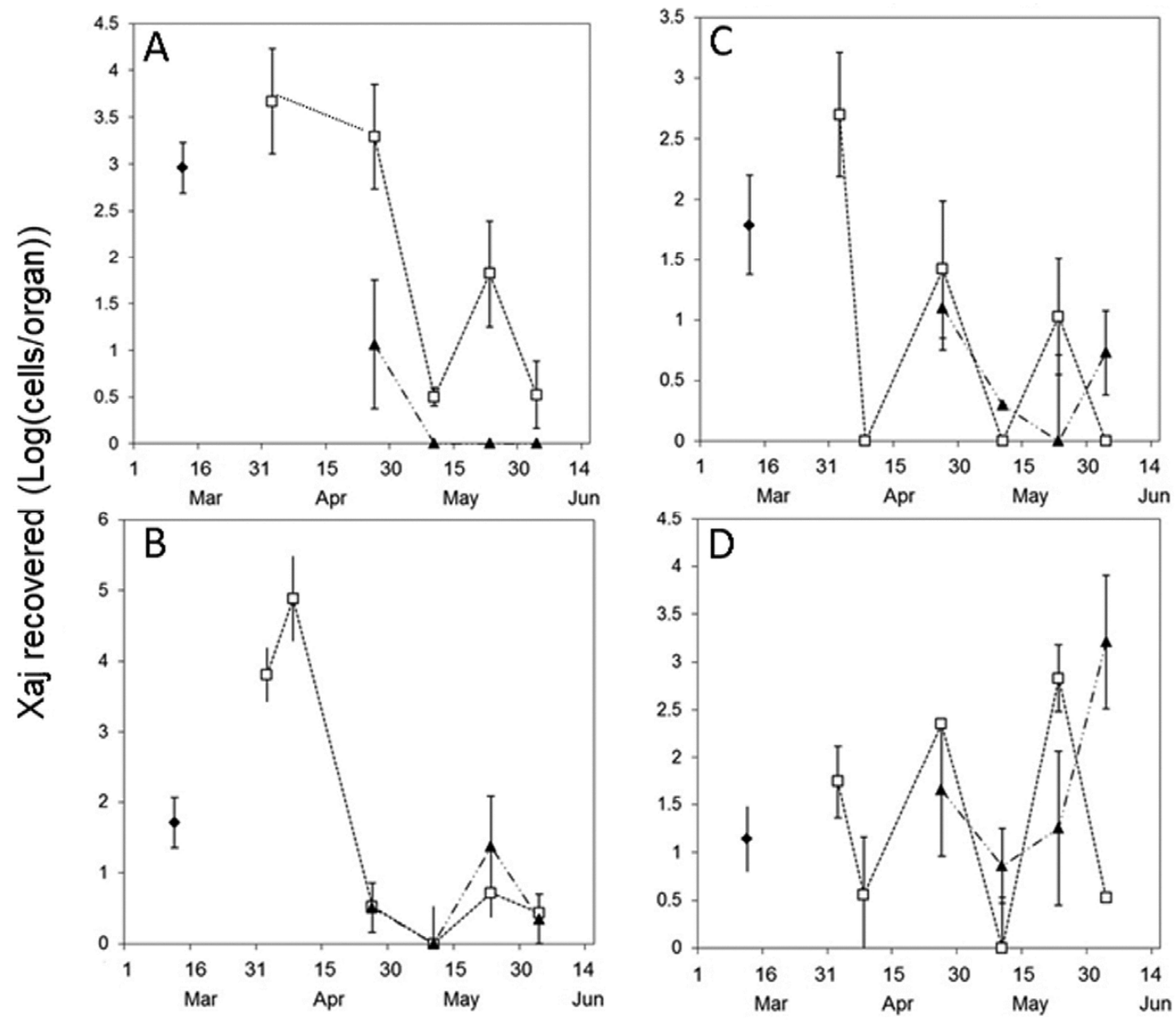

Fig. 2. Population size of Xanthomonas arboricola pv. juglandis on dormant walnut buds (squares), shoots on which developing buds had been excised (circles), and developing nuts (triangles) on untreated trees in commercial orchards $\mathbf{A}, 3 ; \mathbf{B}, 4 ; \mathbf{C}, 2 ;$ and $\mathbf{D}, 8$ located in northern California when sampled at various times throughout spring 1996, as shown on the abscissa. Vertical bars represent the standard error of the determination of mean log-transformed population sizes of $X$. arboricola pv. juglandis for 10 replicate samples of each organ sampled. 
exhibited a similarly wide range of sizes, with a mean $\approx 10$-fold higher than that on 25 May but with a similar variance, as indicated by cumulative normal probability plots with similar slopes (Fig. 3). It can be inferred that, on average, the population size of the bacteria increased $\approx 10$-fold on all buds in both orchards in this time interval. In contrast, although a wide range of population sizes was also observed on 17 August and 21 September, respectively, these populations were no longer described by simple distribution with a uniform variance (Fig. 3). Although those buds in a given orchard having population sizes greater than $\approx 10^{4}$ cells/bud were described by a log-normal distribution with a similar variance as before, those buds having less than $\approx 10^{4}$ cells/bud exhibited a much higher apparent variance, with many buds having undetectably low $X$. arboricola pv. juglandis population sizes (Fig. 3). These results suggest strongly that those factors that caused a reduction in population sizes of $X$. arboricola pv. juglandis did not operate uniformly on the population of buds. Those buds that had originally harbored low populations of the pathogen were apparently not capable of maintaining this population under the adverse conditions which apparently occurred during the late summer months. We posit that those $X$. arboricola pv. juglandis cells that were found in relatively low population sizes on or in buds were more ephemeral, possibly because of a more superficial location in or on the bud.

Further support for the model that $X$. arboricola pv. juglandis population sizes on dormant buds contribute to the populations on shoots that develop from those buds was obtained from repeated measures of $X$. arboricola pv. juglandis populations on buds and shoots of untreated trees in 12 commercial walnut orchards in northern California over a several-year period. As was seen on developing buds during summer months, the population size of $X$. arboricola pv. juglandis on individual dormant buds shortly before opening varied dramatically. For example, when assessed on 25 March 1995, population sizes of X. arboricola pv. juglandis $>10^{7}$ cells/bud were found in some buds of orchard 5 whereas they were undetectably low on other buds (Fig. 4A). Population sizes of $X$. arboricola pv. juglandis in these orchards often were higher in 1995 than in the same and other orchards in subsequent years and varied greatly between different orchards (Supplemental Figure 1). Many buds in each of the orchards sampled in 1995 had undetectable populations of $X$. arboricola pv. juglandis whereas some buds in most orchards had population sizes $>10^{6}$ cells/bud (Fig. 4A). The average population size of $X$. arboricola pv. juglandis on buds differed substantially in the various orchards before bud break (Fig. 4A). Although $X$. arboricola pv. juglandis was not detected on any buds in orchard 6 , average population sizes were nearly $10^{5}$ cells/bud in orchards 11 and 4 . Population sizes of $X$. arboricola pv. juglandis on many young shoots were $>10^{7}$ cells/shoot when assessed on 4 April in many orchards, especially in orchards 11,12 , and 5 , which previously harbored large population sizes of $X$. arboricola pv. juglandis on their buds (Fig. 4B). At the same time, many shoots in all orchards harbored no detectable populations of X. arboricola pv. juglandis (Fig. 4B). The relative population size of $X$. arboricola pv. juglandis in each orchard compared with that in other orchards remained constant throughout the spring. For example, there was a strong correlation between the population size on individual dormant buds in a given orchard on 10 March and that measured in the same orchards on 25 March (Fig. 5A). Regression analysis revealed that bud populations differed little when assessed 15 days apart (Fig. 5A). The mean population sizes of $X$. arboricola pv. juglandis recovered from individual buds shortly before they opened was also highly correlated with the mean population sizes on young shoots in a given orchard measured 10 days later (Fig. 5B). The mean population sizes of $X$. arboricola pv. juglandis on individual shoots varied greatly between the orchards; whereas mean population size on shoots in orchards 6, 10 , and 9 was approximately only $10^{4}$ cells/shoot, the mean popu- lation size in orchard 11 was $>10^{7}$ cells/shoot. The mean population size of $X$. arboricola pv. juglandis on young shoots in 1995 was always somewhat higher than that on buds measured 10 days earlier (Fig. 5B). These results contrast somewhat with that of a similar 1996 study, in which bud population sizes were often similar to those on developing shoots (Fig. 2). It should be noted, however, that spring 1995 experienced more rainfall events than 1996 (10 and 4 rainfall events in April, respectively). However, in both years, the strong correlation between dormant bud populations of $X$. arboricola pv. juglandis and the population size of the pathogen on emergent shoots supported a model of direct transfer of inoculum from buds to the shoots.

Linkage of $X$. arboricola pv. juglandis populations on nuts with those on buds and shoots. We measured the population size
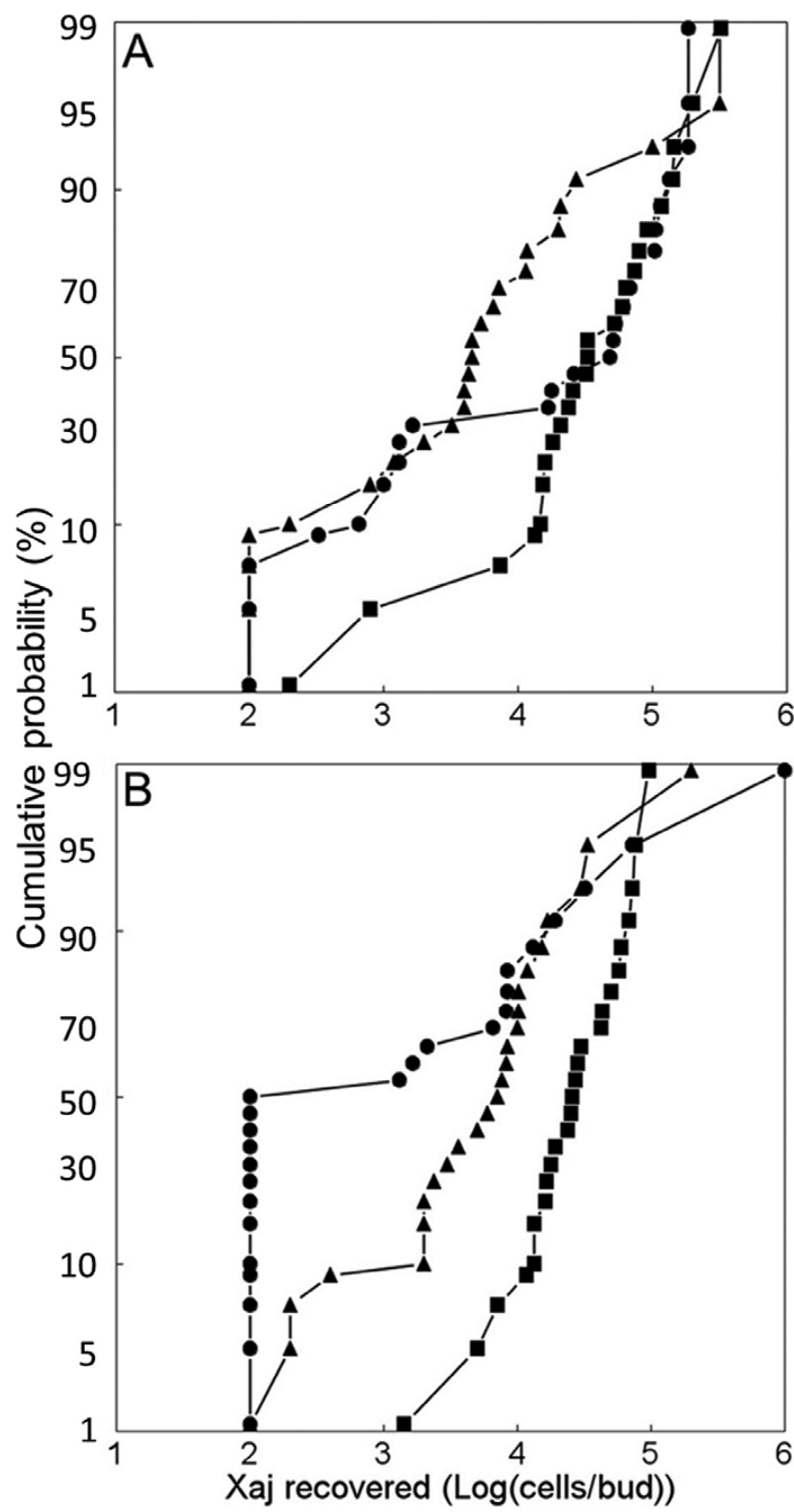

Fig. 3. Population size of Xanthomonas arboricola pv. juglandis on individual developing buds on untreated walnut trees in $\mathbf{A}$, orchard A when sampled on 25 May (squares), 17 June (circles), or August 17 (triangles); or B, orchard B when sampled on 25 May (squares), 17 June (circles), or 21 September (triangles) in 1994. Shown is the cumulative proportion of 25 individual buds having a log-transformed population size less than that of the values shown on the abscissa at a given sampling time. 
of $X$. arboricola pv. juglandis on a large number of individual shoots as well as on nutlets that were developing on each of those shoots to address whether nut populations of $X$. arboricola $\mathrm{pv}$. juglandis were related to numbers of $X$. arboricola pv. juglandis on nearby leaves and shoots. Developing nuts were excised from a given shoot on 4 April 1995 from untreated trees in 12 different orchards and $X$. arboricola pv. juglandis population size was measured separately on the nut and remaining shoot. A large proportion of the nuts collected from these orchards had undetectable population sizes of X. arboricola pv. juglandis (Fig. 6). Importantly, however, many of those nuts were borne on shoots on which $X$. arboricola pv. juglandis was also undetectable (26 of 153 shoots with at least one nut). However, $>40$ nuts lacking
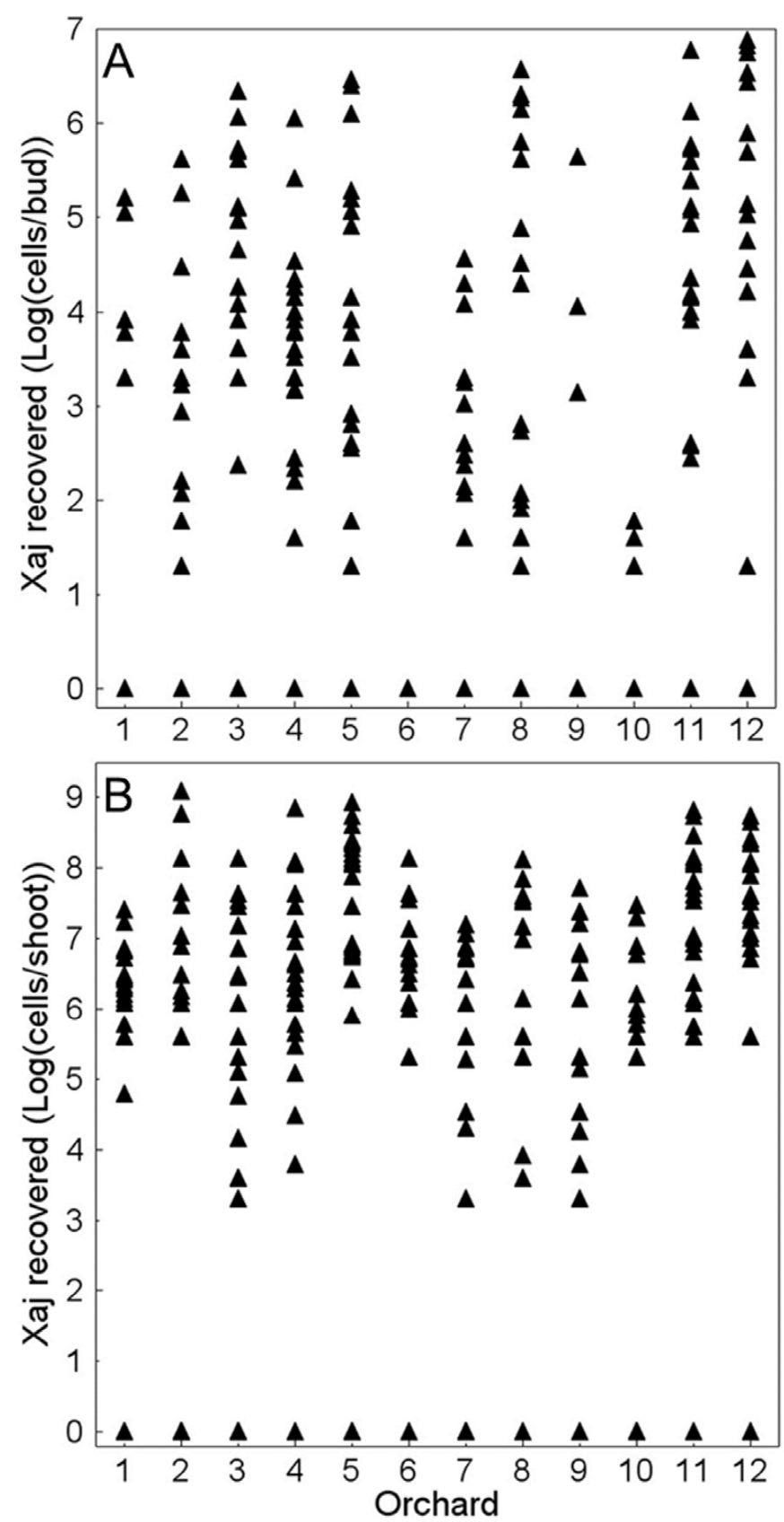

Fig. 4. Population size of Xanthomonas arboricola pv. juglandis A, on individual dormant buds collected from untreated walnut trees in each of 12 commercial orchards in northern California on 25 March 1995 or B, from individual developing shoots in the same orchards on 4 April 1995. Each point represents the log-transformed population size for an individual bud or shoot in a given orchard. Samples for which $X$. arboricola pv. juglandis was undetected were assigned the value of 0 . detectable $X$. arboricola pv. juglandis were on shoots having detectable populations of $X$. arboricola pv. juglandis (Fig. 6). It is likely that transfer of inoculum from buds to nuts failed to occur in such instances. Although infested shoots did not invariably lead to infestation of the associated nuts, the population size of $X$. arboricola pv. juglandis on the infested nuts was generally proportional to $X$. arboricola $\mathrm{pv}$. juglandis population size on the
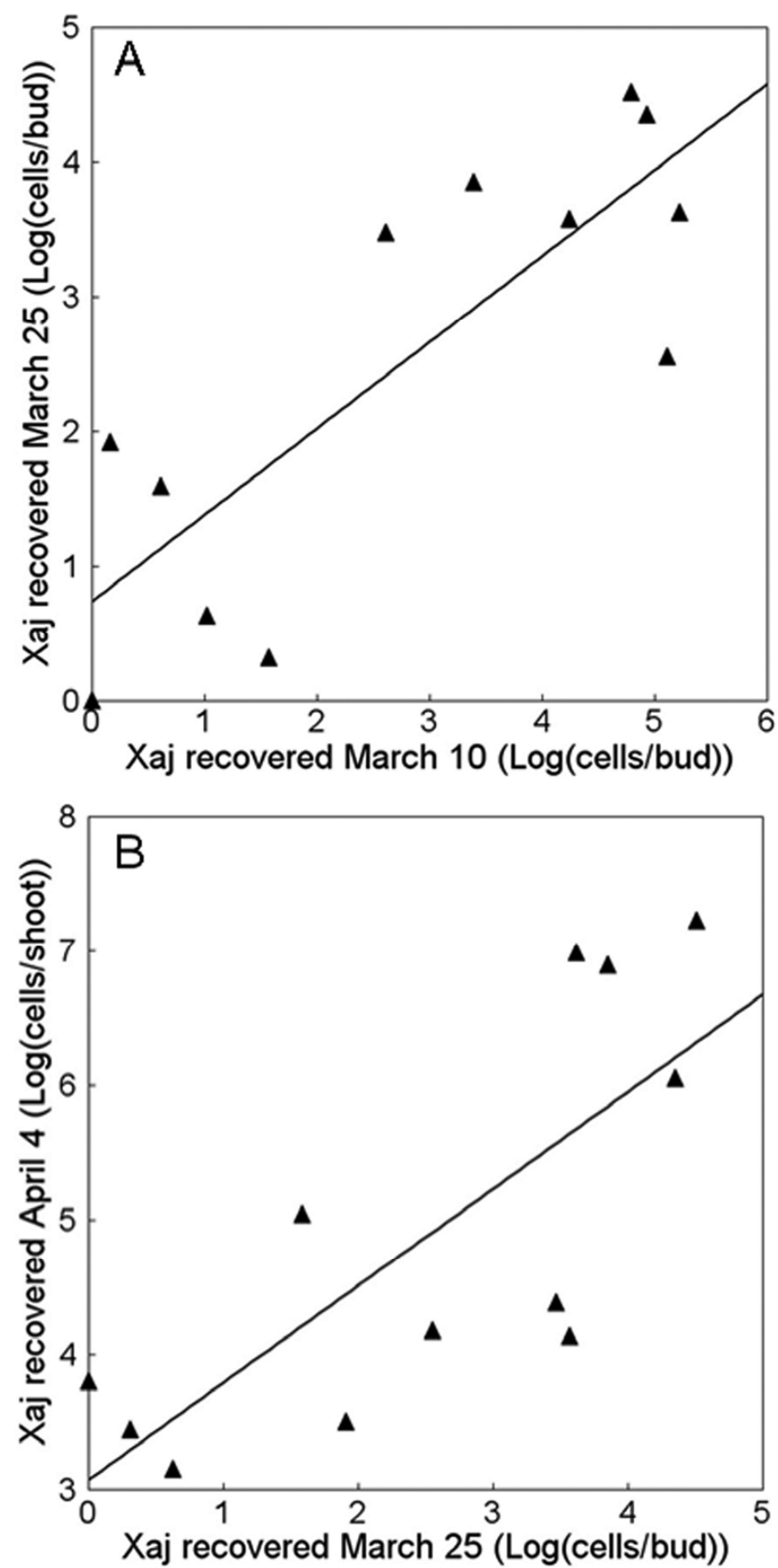

Fig. 5. A, Relationship between mean population size of Xanthomonas arboricola pv. juglandis on individual dormant walnut buds sampled on 10 March 1995 from untreated walnut trees in 1 of 12 different commercial orchards located in northern California (abscissa) with the mean population size recovered from buds in the same orchard when sampled on 25 March 1995 (ordinate). B, Also shown is the relationship between mean population size of $X$. arboricola pv. juglandis recovered from individual buds on 25 March 1995 with the mean population size on developing shoots from trees in the same orchards on 4 April 1995. At each sampling time, X. arboricola pv. juglandis population size on 25 individual buds or developing shoots was measured. Lines drawn represent the linear regressions $Y=0.63 x+0.74\left(R^{2}=\right.$ $0.65, P=0.0013)$ and $Y=0.72 x+3.08\left(R^{2}=0.59, P=0.0035\right)$, respectively. 
shoot (Fig. 6); those nuts borne on shoots having the highest population size of $X$. arboricola pv. juglandis harbored nuts with the highest $X$. arboricola pv. juglandis populations. Very few nuts harboring $X$. arboricola pv. juglandis were borne on shoots not having detectable $X$. arboricola pv. juglandis. Because of the three-dimensional structure of walnut canopies, it is likely that adjacent shoots might actually be in closer proximity to such nuts than the shoot on which they were borne. This could account for the presence of some nuts having detectable population sizes of $X$. arboricola pv. juglandis despite the fact that they formed on shoots which themselves were not infested with the pathogen. Thus, it appears that there is a strong association between the population size of $X$. arboricola pv. juglandis on individual nuts and the population sizes on nearby leaves. Because the population sizes of $X$. arboricola pv. juglandis on shoots is also strongly associated with its population size in the buds from which they were derived (Fig. 5B), there also appears to be a strong association of pathogen populations in buds with that on nuts. That is, infestation of a nut is unlikely unless the shoot and, thus, the parental bud is infested.

Disease incidence predicted from populations of $X$. arboricola pv. juglandis in buds. The incidence of disease in each of the several orchards for which the population sizes of $X$. arboricola pv. juglandis had been assessed on buds and shoots during spring 1995 was measured in early June to determine whether disease could be predicted from such measures of pathogen abundance. The incidence of disease varied substantially (more than fivefold) between the various orchards but was strongly correlated with the mean population size of $X$. arboricola pv. juglandis measured on emerging shoots in early April (Fig. 7B). The incidence of disease was also strongly correlated with population sizes of $X$. arboricola pv. juglandis on dormant walnut buds 10 days earlier (25 March) (Fig. 7A) or 24 days earlier (data not shown). The mean log-transformed population size of $X$.

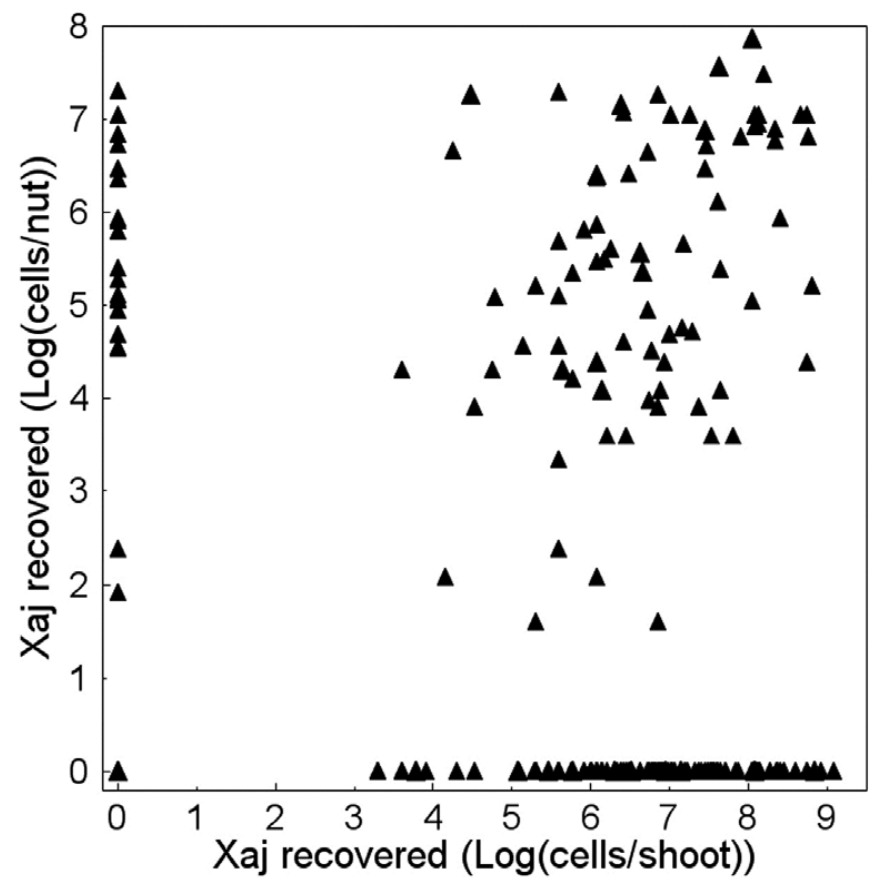

Fig. 6. Relationship between the population size of Xanthomonas arboricola pv. juglandis on individual developing shoots of untreated walnut trees in 12 different orchards in northern California on 4 April 1995 and the population size of $X$. arboricola pv. juglandis on developing nutlets borne on that same shoot. Nuts were removed from individual shoots from each orchard and population sizes on shoots and nuts were separately assessed. Each symbol represents population size of $X$. arboricola pv. juglandis on nuts associated with a particular shoot. Note that, for 26 shoots, X. arboricola pv. juglandis was undetectable on both the shoot and nut.
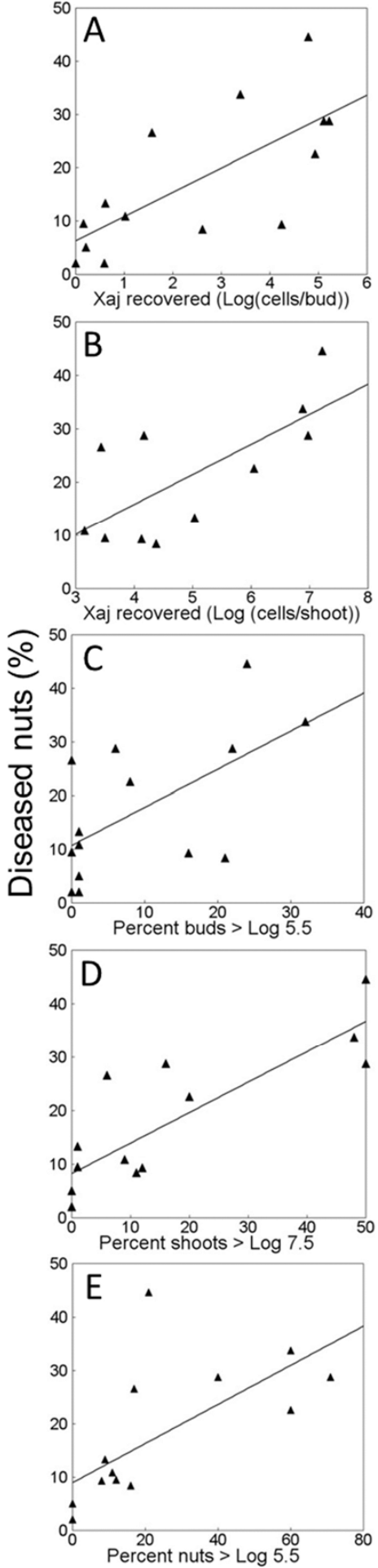

Fig. 7. Relationship between mean population size of Xanthomonas arboricola pv. juglandis determined on A, dormant walnut buds on 25 March 1995 or B, newly emerging shoots measured on 4 April 1995 and the incidence of disease on nuts measured on 1 June. Each point represents the mean of measurements from 25 samples from a given orchard. Lines drawn represent the linear relationships $Y=4.57 x+6.2\left(R^{2}=0.38, P=0.0035\right)$, and $Y=5.63 x$ $-6.72\left(R^{2}=0.51, P=0.14\right)$ between mean $\log$ transformed $X$. arboricola $\mathrm{pv}$. juglandis population size on $\mathbf{A}$, buds or $\mathbf{B}$, shoots, respectively. Also shown is the relationship between $\mathbf{C}$, the percentage of dormant walnut buds harboring population sizes of $X$. arboricola pv. juglandis $>10^{5.5}$ cells/bud on $25 \mathrm{March}$ 1995 ; D, the percentage of shoots harboring population sizes of $X$. arboricola pv. juglandis $>10^{7.5}$ on April 4; or $\mathbf{E}$, the percentage of developing nutlets harboring population sizes of $X$. arboricola pv. juglandis $>10^{5.5}$ cells/nut on 4 April and the proportion of nuts that were infected on 1 June. Lines drawn represent the linear relationship $Y=0.71 x+10.7\left(R^{2}=0.36, P=0.02\right), Y=$ $0.57 x+8.2\left(R^{2}=0.69, P=0.0002\right)$, and $Y=0.37 x+8.94\left(R^{2}=0.45, P=\right.$ 0.008 ) illustrated in $\mathrm{C}, \mathrm{D}$, and $\mathrm{E}$, respectively. 

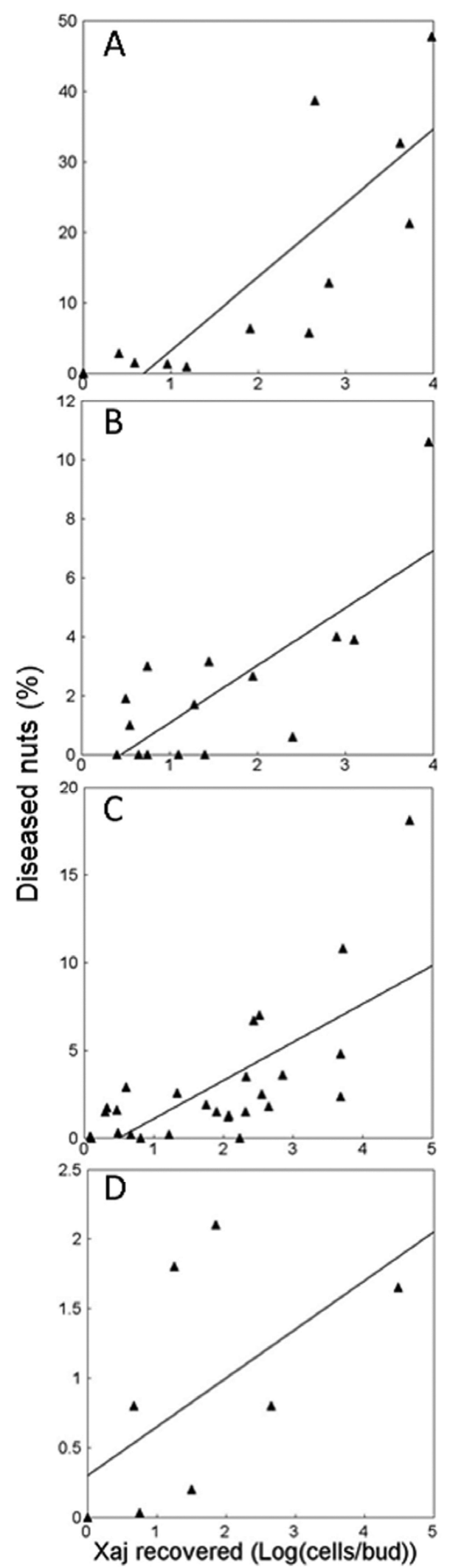

Fig. 8. Relationship between mean population size of Xanthomonas arboricola pv. juglandis on dormant walnut buds measured in mid-March A, 1998; B, 1999; C, 2000; and D, 2002 on untreated walnut trees in a variety of commercial orchards in northern and central California and the incidence of disease on nuts measured in early June. Each point represents the mean of 10 replicate samples from a given orchard. Lines drawn represent the linear relationships $Y=10.47 x-7.25\left(R^{2}=0.70, P=0.018\right) ; Y=1.95 x-0.87\left(R^{2}=\right.$ $0.57, P=0.001) ; Y=2.18 x-1.08\left(R^{2}=0.49(P<0.0001) ;\right.$ and $Y=0.35 x-0.30$ $\left(R^{2}=0.44, P<0.005\right)$ for years $1998,1999,2000$, and 2002 , respectively. arboricola pv. juglandis on dormant buds was strongly linearly related to the incidence of colonization of those buds (Supplemental Figure 2); therefore, we posited that the incidence of disease would also be strongly related to the incidence of infestation of buds by $X$. arboricola pv. juglandis. Because population sizes of $X$. arboricola pv. juglandis on dormant buds were described by a log-normal distribution (Supplemental Figure 3), it was possible to estimate the proportion of buds having a population size greater than a given value from the linear relationship between the cumulative percentage of buds having a given logtransformed population size and the expected normal score. Therefore, using the incidence of infestation of buds by $X$. arboricola pv. juglandis as a proxy, we assessed the relationship between nut disease incidence and various intensities of bud colonization. A similarly significant correlation between the percentage of dormant buds harboring $>10^{5.5}$ cells/bud and the incidence of disease of nuts (Fig. 7A), compared with the correlation between the percentage of shoots harboring $>10^{7.5}$ cells/ shoot (Fig. 7D) or between the percentage of nuts harboring $>10^{5.5}$ cells/nut (Fig. 7E) and the incidence of disease, was observed. The relationship observed between the incidence of disease and the proportion of developing nuts having a given population size when assessed in early April (Fig. 7C), while highly significant, was no stronger than that observed between mean population sizes of $X$. arboricola pv. juglandis on buds (Fig. 7A). In other years, the relationships between the proportion of buds having greater than a particular threshold population size of the pathogen or the proportion of shoots having more than a given threshold population size of $X$. arboricola pv. juglandis and incidence of subsequent nut disease were equally strong (Supplemental Figure 4). Thus, population sizes of $X$. arboricola pv. juglandis on dormant buds are predictive of the incidence of subsequent disease on nuts and enable such predictions to be made much earlier than from shoot populations.

To determine the robustness of the relationship between $X$. arboricola pv. juglandis population sizes on dormant buds and subsequent disease, pathogen abundance on buds before they opened and subsequent disease was assessed in several additional orchards in northern and central California over a period of several years. The incidence of disease on nuts in June was always strongly correlated with mean log-transformed population size of $X$. arboricola pv. juglandis in buds measured in early March (Fig. 8). Invariably, the lowest population sizes of $X$. arboricola pv. juglandis were associated with the lowest incidence of disease while those orchards having the highest incidence of disease usually had the highest population sizes of $X$. arboricola pv. juglandis in buds in that year (Fig. 8). It was noteworthy, however, that the slope of these linear relationships differed substantially from year to year. For example, in 1998, a given population size of $X$. arboricola pv. juglandis was associated with a much higher incidence of disease (Fig. 8A) than in years such as 2002 (Fig. 8D). The degree to which the incidence of disease increased with increasing log population size of $X$. arboricola pv. juglandis differed by $>10$-fold from one year to the next (Fig. 9). The slope of this relationship might be considered a measure of "inoculum efficiency".

Effects of weather conditions on inoculum efficiency. Weather conditions varied substantially from year-to-year, and was associated with the different apparent inoculum efficiency seen in different years. Mean daily temperatures varied somewhat between these locations within a given year. A strong relationship between mean population size of $X$. arboricola pv. juglandis and incidence of disease was seen in a given year despite such apparent differences in temperature; therefore, it seemed unlikely that temperature was a strong driver of the apparent differences in inoculum efficiency seen between years. In contrast, although most orchards experienced a similar frequency of rainfall events during the early growing season of a given year, the number of 
rainfall events varied substantially from year to year. For example, in 2002, only one rainfall event occurred between 1 April and 30 June whereas, in 1998, rainfall during this period occurred on 21 days. We posited that rainfall was needed to move inoculum present in or on dormant buds to developing shoots and, ultimately, to nuts. Because nuts begin to form within $\approx 2$ weeks of bud break, we further reasoned that rainfall events occurring soon after bud break would be more essential for the movement of inoculum from buds to shoots and nuts than later events. To test this hypothesis, we examined how the slope of the linear relationship between the incidence of disease and mean logtransformed $X$. arboricola $\mathrm{pv}$. juglandis population size in a given year (inoculum efficiency) was influenced by the number of days during April (Fig. 10A) or May (Fig. 10B) that rainfall events occurred in a given year. A strong linear relationship between inoculum efficiency and the number of days in April in which rain occurred in a given year was observed (Fig. 10A). Although a positive relationship between inoculum efficiency and the number of days in May in which rain fell in a given year was also observed, statistical support for such a connection was much weaker (Fig. 10B). Although a significant relationship was seen between inoculum efficiency and the frequency of April rainfall $(P=0.03)$, no such significant relationship was seen with the amount of rain in May $(P=0.11)$ (data not shown). Therefore, it appears that both the frequency with which buds and shoots are wetted soon after buds open as well as the population size of $X$. arboricola pv. juglandis in those buds are strong predictors of the likelihood that nuts will encounter bud-derived inoculum and, thus, the probability of disease.

Direct linkage of bud population sizes of $X$. arboricola pv. juglandis and disease. Although the results described above enabled us to develop a robust model of bud-driven nut infection, the evidence is somewhat indirect because pathogen populations were assessed on different cohorts of buds. Because the assessment of $X$. arboricola pv. juglandis populations on buds was done in a destructive manner, we could not determine their numbers on shoots or nuts derived from those same buds. To more directly link inoculum of $X$. arboricola pv. juglandis in dormant buds to nut infections, bud scales harboring $X$. arboricola pv. juglandis were delicately removed before bud break from 100 buds from untreated trees in a commercial orchard to nondestructively determine pathogen presence. As when whole buds were sampled, the population size of $X$. arboricola pv. juglandis in the excised bud scales varied greatly from bud to bud. Although the pathogen was not detected in over half of the buds, some buds harbored $>10^{5}$ cells/bud. Cohorts of buds varying in the population size of $X$. arboricola pv. juglandis they harbored prior to bud break were thereby identified. At weekly intervals after bud break, the incidence of infection of nuts that developed from each bud in a given cohort was determined. Although no nuts arising from buds harboring less than $\approx 10^{4}$ cells/bud became infected by June 2002 , $\approx 35 \%$ of the buds harboring at least $10^{5.5}$ cells/bud gave rise to nuts that subsequently became infected (Fig. 11). The proportion of nuts that became infected increased with increasing $X$. arboricola pv. juglandis bud population sizes $>10^{4}$ cells/bud (Fig. 11). A similar study done in a second year also found that nut infection was very unlikely unless buds harbored $>10^{3.5}$ cells of $X$. arboricola pv. juglandis (data not shown). Thus, not only did buds in a close spatial relationship to one another harbor greatly different population sizes of $X$. arboricola pv. juglandis but also the likelihood of disease on nuts derived from such buds was predicted by the abundance of the pathogen in that bud.

\section{DISCUSSION}

Inoculum of $X$. arboricola pv. juglandis resident in or on walnut buds appears to play a central role in the epidemiology of walnut blight disease. Although walnut leaves and nuts are relatively ephemeral tissues, buds are present on walnut trees at nearly all times of the year. The colonization of buds by $X$. arboricola pv. juglandis appears to occur very soon after their formation in the spring (Fig. 1) and, given that infestation of buds can be observed at all times of the year, it is presumed that, once the pathogen is associated with buds, it usually remains a permanent resident. Considerable circumstantial evidence suggests that $X$. arboricola pv. juglandis is not a good epiphyte on walnut tissues. It was striking to note that the total population size of $X$. arboricola pv. juglandis was often as high on relatively small

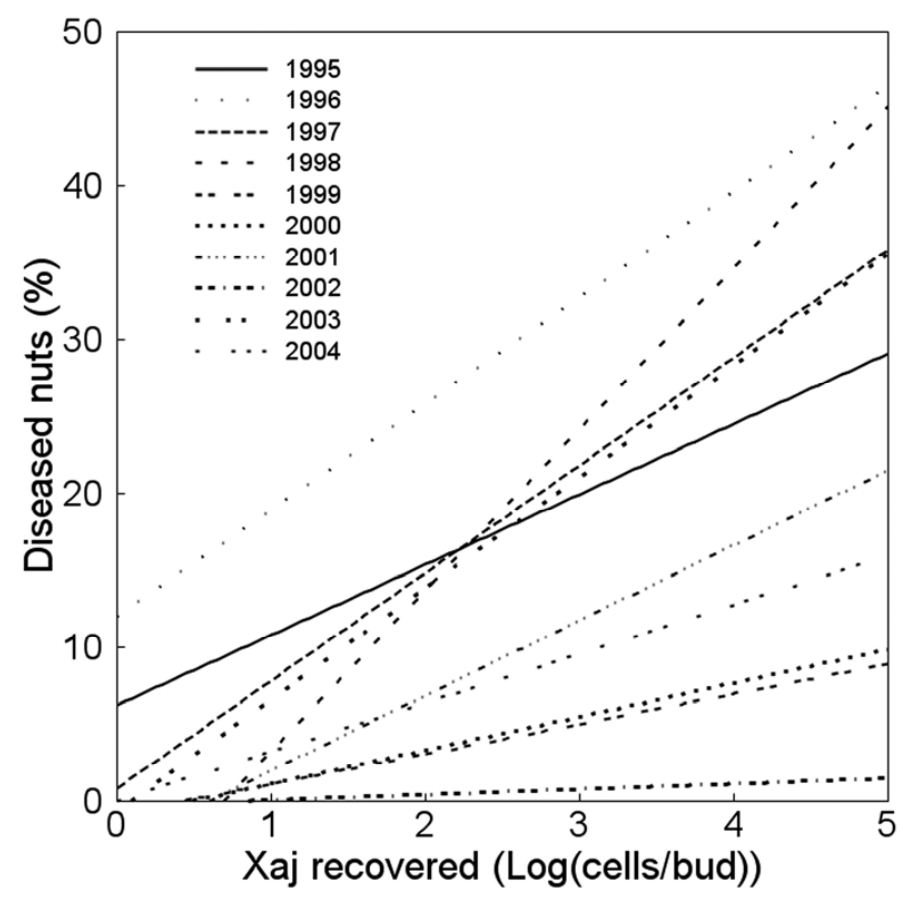

Fig. 9. Relationship between mean population size of Xanthomonas arboricola pv. juglandis on dormant walnut buds measured in mid-March in each of several years and the incidence of nut infections measured in early June. 
dormant buds as it was on the large shoots that developed from such buds (Figs. 1 and 2). Thus, on a per-mass basis, the population size of $X$. arboricola pv. juglandis in or on buds is at least 50 -fold higher than that on leaves. This study did not address whether X. arboricola pv. juglandis was present only on the surface of buds or whether it also occurred within buds. Given that there is no evidence for necrosis or other abnormal development of $X$. arboricola pv. juglandis-infested buds, it seems likely that this pathogen colonizes only the surface of asymptomatic walnut tissues, such as within buds. It would be expected that cells colonizing the surface of tissues within the bud would be protected from both desiccation and ultraviolet light, two major factors that limit survival of bacteria on leaf surfaces $(14,15)$. It was somewhat surprising that $X$. arboricola pv.
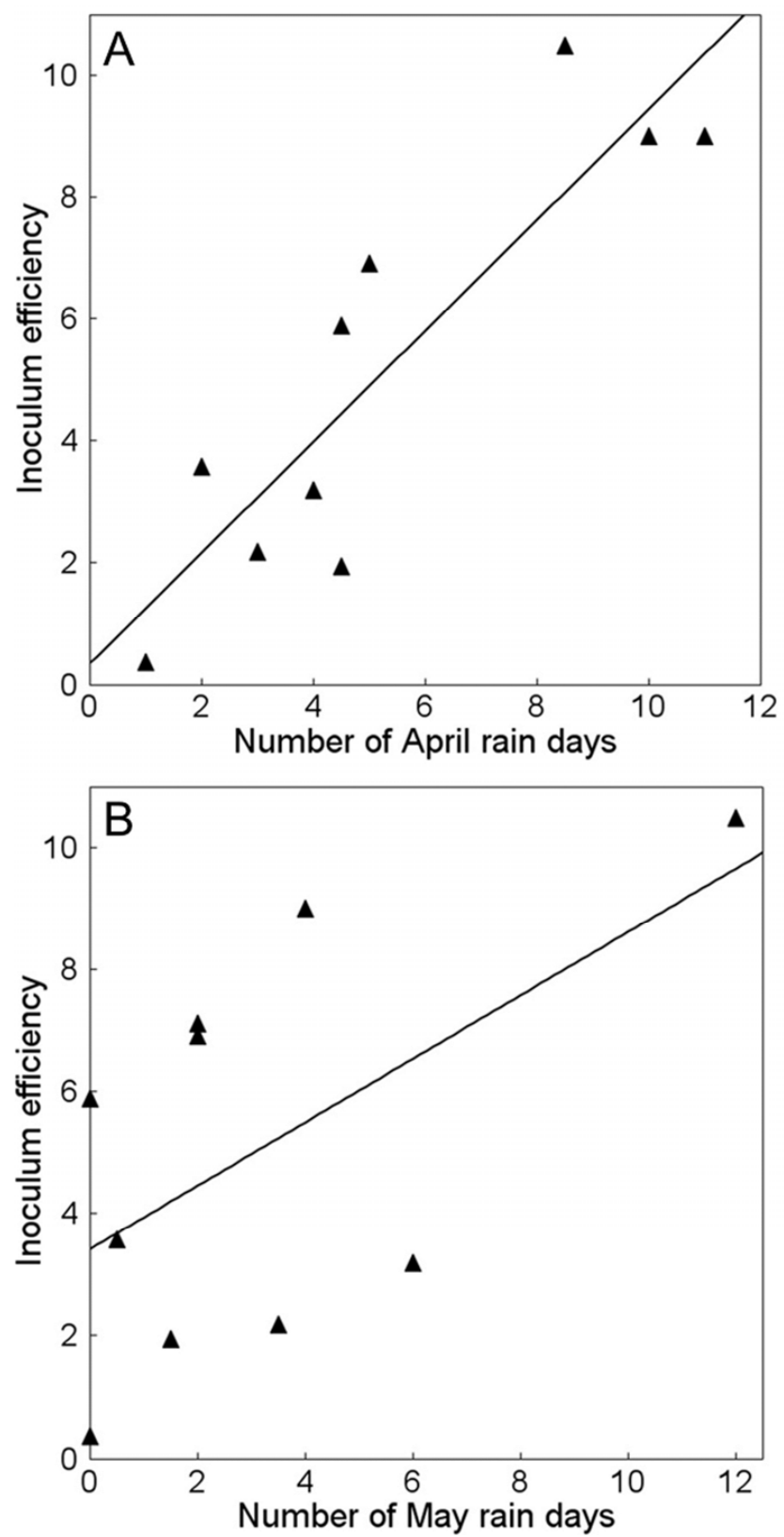

Fig. 10. Relationship between inoculum efficiency, measured as the slope of the regression of incidence of nut infections, against the mean log-transformed population size of Xanthomonas arboricola pv. juglandis on dormant buds measured in mid-March for each of several years and the number of days in A, April or B, May on which measurable rainfall was recorded in the plot area. Lines drawn represent the linear relationships $Y=0.91 x+0.35\left(R^{2}=0.77, P=\right.$ $0.0007)$, and $Y=0.51 x+3.42\left(R^{2}=0.31, P=0.086\right)$ for the number of rainy days in April and May, respectively. juglandis populations increased in buds even during the hot, dry summer months characteristic of the interior valleys of California, where these studies were conducted (Figs. 1 and 3). Such conditions would not be conducive to the growth or survival of $X$. arboricola pv. juglandis on exposed leaves. Indeed, population sizes of $X$. arboricola pv. juglandis on shoots generally did not increase soon after their formation (Figs. 1 and 2). In contrast, the increases in population size seen in buds over this time period suggests that they flourished on surfaces protected within buds. As such, $X$. arboricola pv. juglandis might best be considered an epiphyte of the developing leaves contained within the bud. Further study of the localization of $X$. arboricola pv. juglandis in and on buds is warranted. Such information should enable the development of more explicit models of the process of transfer of inoculum from dormant buds to developing buds, shoots, and nuts.

Population sizes of $X$. arboricola pv. juglandis on various parts of walnut trees exhibited a strikingly high level of spatial heterogeneity. Although population sizes on individual organs such as buds or leaves were described by a log-normal distribution, similar to that seen in other plant-pathogenic bacteria such as Pseudomonas syringae and Erwinia amylovora (8-10), the range of population sizes observed was greater than that typically seen in other taxa. Although some dormant buds harbored $>10^{7}$ cells/bud, population sizes were undetectable $(<10$ cells/bud) on others in the same tree (Fig. 4). Such high variation in population size of $X$. arboricola pv. juglandis on such a long-lived organ is perhaps unexpected. Although the factors that lead to variations in population size of $P$. syringae on bean leaves remain unclear, it has been suggested that differences in the order of arrival of immigrants to leaves and, thus, differential success in immigration and growth could account for such log-normal distributions $(8,9,25)$. It should be noted, however, that the outermost layers of bean canopies, the subject of such studies, is probably subject to much less leaf-to-leaf sharing of inoculum because of its young age and relatively small vertical dimensions, although some evidence for such a process has been observed (25). As such, immigration and growth processes on individual bean leaves

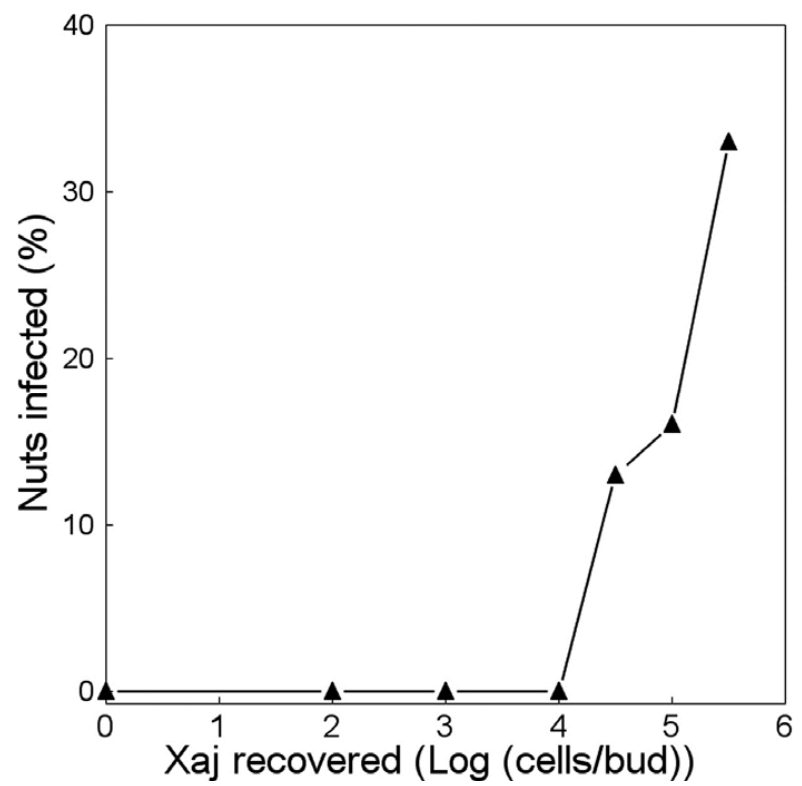

Fig. 11. Relationship between population size of Xanthomonas arboricola pv. juglandis in the outermost scales of dormant buds from untreated trees in a commercial Ashley walnut orchard that was semidestructively sampled in February 2002 and the fraction of nuts that arose from those sampled buds that exhibited disease in early June. Of the buds sampled, 6 harbored $<10^{2}$; $8>10^{2}$ but $<10^{3} ; 5>10^{3}$ but $<10^{4} ; 6>10^{4}$ but $<10^{4.5} ; 15>10^{4.5}$ but $<10^{5}$; $36>10^{5}$ but $<10^{5.5}$; and $24>10^{5.5}$ but $<10^{6}$ cells/bud. 
may occur relatively independent of one another. In contrast, walnut buds form on large trees in which there is much potential for vertical and horizontal sharing of inoculum due to rain splash and other dispersal mechanisms. Over the nearly 12-month life of a bud, one might expect much more opportunity for dispersal of inoculum between such buds compared with the relatively short period of time over which colonization of bean leaves had been considered. The lack of homogenization of $X$. arboricola pv. juglandis populations in buds over time suggests that they may be susceptible to invasion by $X$. arboricola pv. juglandis for only for a short time during their formation. The fact that they harbor relatively large population sizes of $X$. arboricola pv. juglandis soon after their formation in the spring is supportive of such conjecture. More detailed study of the process of bud colonization is needed to develop more explicit models of the colonization process. Likewise, more information on the processes that lead to colonization of developing shoots is needed to explain why many shoots can apparently remain free of infestation by $X$. arboricola pv. juglandis when other nearby shoots in the three-dimensional canopy of walnut trees are heavily colonized (Fig. 4B).

Although walnut trees consist of long-lived tissues such as buds, the processes that lead to disease development are probably constrained to a period of a few weeks, starting at the time of bud break. In the Mediterranean climate of California, rainfall becomes increasing unlikely with time after bud break which, for the varieties studied here, occurs in late March. Rainfall events are very unlikely after mid-May. Although temporal measurement of disease occurrence on nuts was not a focus of this study, prior observations revealed that most disease development on nuts became apparent by early May and little further incidence of symptoms occur after $>3$ weeks later $(20,21)$. Disease progress curves for walnut blight in Australia also reveal that disease usually occurred within $\approx 60$ days of bud break and developed over an $\approx 14$-day period (12). Disease symptoms on leaves were seldom observed in our studies, even if a high proportion of nuts had become infected. It is unclear whether disease results from events that occur in discrete time intervals associated with particular environmental conditions, or whether it is a more stochastic process, dependent primarily on pathogen population size on asymptomatic tissues, as for various pathovars of $P$. syringae (9). Regardless of what processes initiate disease, there is only a relatively short period of time during which inoculum, resident primarily in buds, can encounter nuts. Given that buds of the walnut varieties studied open in late March, nuts emerge by early April, and disease occurs as soon as early May (3,20,21), nuts must apparently encounter inoculum soon after their formation on the terminal parts of these developing shoots. Although relatively large population sizes of $X$. arboricola pv. juglandis developed on some shoots and nuts, its successful inoculation of other parts of the tree appeared to be restricted, because many other shoots or nuts on those same trees remained free of colonization (Fig. 4). It seems likely that $X$. arboricola pv. juglandis is dispersed during rainfall events because other plant-pathogenic bacteria have been shown to be spread by rain splash (9). Such transfer apparently does not often result in successful colonization of other plant parts of walnut, perhaps because of the poor epiphytic fitness of $X$. arboricola pv. juglandis, because most shoots that are devoid of $X$. arboricola pv. juglandis gave rise to nuts that were also free of the pathogen (Fig. 6). Even in years such as 1995, in which frequent rainfall occurred and $X$. arboricola pv. juglandis population sizes increased on shoots compared with that on buds earlier (Fig. 5B), its shoot populations were very heterogeneous and many shoots were free of detectable pathogen (Fig. 4B). Thus, although transfer of inoculum of $X$. arboricola pv. juglandis from buds to shoots likely occurs, in many years there is little subsequent multiplication of the inoculum. Successful transfer of $X$. arboricola pv. juglandis, even if it were to subsequently multiply, is probably possible only in a short window of time during shoot and nut development. Because buds that will be the source of the following season's shoots form early in the development of the current season's shoots, disease in a given year is likely to be correlated with that in the previous year. Because buds harboring large population sizes of $X$. arboricola pv. juglandis that open in a given year often give rise to shoots that also harbor the pathogen (Fig. 5B), it is likely that buds forming on those shoots are also more likely to be colonized by the pathogen. Likewise, orchards having relatively low bud populations of $X$. arboricola pv. juglandis likely will produce new buds that also have relatively low numbers of the pathogen in the subsequent year. Thus, disease potential might be expected to oscillate somewhat slowly from year to year compared with other pathosystems. Orchard management schemes also seem to play a large role in determining disease risk, because both the population sizes of $X$. arboricola pv. juglandis and disease incidence in a given year varied substantially in the orchards surveyed, despite the fact that they were in close proximity and usually of the same walnut cultivars (Figs. 4 and 7). Further work to elucidate roles of historical use of pesticides and environmental factors that might influence population dynamics in buds should be informative and might be exploited for disease control.

The persistent spatial heterogeneity of $X$. arboricola pv. juglandis in walnut trees suggests that trees are composed of thousands of individual infection courts where interaction between the pathogen and nuts are occurring. Some nuts, presumably those near shoots having relatively high population sizes of $X$. arboricola pv. juglandis, will harbor many cells of the pathogen, while other nuts harbored on shoots lacking inoculum (and, thus, usually derived from buds also lacking inoculum) will be free of the pathogen and escape infection. Support for such a model was provided by the data described in Figure 6 that revealed that $X$. arboricola pv. juglandis was very unlikely to be found on nuts unless the shoots on which they were born were also colonized. In a more direct demonstration of the necessity for bud colonization by $X$. arboricola $\mathrm{pv}$. juglandis, we found that nut infection did not occur if the particular bud from which they developed harbored less than $\approx 10^{4}$ cells (Fig. 11). Studies designed to determine the processes that lead to the highly variable population sizes of $X$. arboricola pv. juglandis seen on buds are justified, given their apparent importance as initial inoculum. The process by which $X$. arboricola pv. juglandis is apparently transferred from buds to developing nuts should also be further investigated. The frequency with which developing shoots are wetted by rainfall appears to be positively associated with the efficiency with which inoculum present in the bud leads to nut infections (Fig. 10A). Thus, it is tempting to speculate that the primary role of rain is to act as a physical conveyor of $X$. arboricola pv. juglandis cells from bud tissue as it opens to developing shoots and, eventually, to the nuts that form on the distal portion of the shoot. If $X$. arboricola pv. juglandis colonizes leaves within buds, rain may merely be needed to move inoculum from the developing leaves and shoots to the nut, assuming that it was initially free of the pathogen. More knowledge of the location of $X$. arboricola pv. juglandis within buds should clarify the transmission process.

The finding of a strong positive correlation between population sizes of $X$. arboricola pv. juglandis in dormant buds and subsequent incidence of infection of nuts (Fig. 8) offers the promise that assessments of the distribution of pathogen abundance in buds can be used to predict the potential for disease in a given orchard. Although the risk of disease can also be predicted from prior estimates of pathogen abundance in developing shoots (Fig. 8), predictions based on population sizes of $X$. arboricola pv. juglandis in buds might be more practical because it is present in stable population sizes in buds for many weeks before bud break (Figs. 1 and 5A). Therefore, it might be possible to determine disease risk well before protective bactericides might need to be applied by assessing either the incidence or mean population 
sizes of $X$. arboricola pv. juglandis in individual dormant buds. Although disease would be unlikely in orchards having a low incidence of infestation of buds by $X$. arboricola pv. juglandis, relatively high frequencies of infestation of buds does not necessarily ensure that disease will occur, because the frequency of rainfall strongly influences the incidence of disease given a given population size of the pathogen (Fig. 10). Bactericide treatments commonly used for control of walnut blight disease would appear to be less necessary in orchards having relatively low population sizes of the pathogen. Although population sizes of several plant pathogens on asymptomatic plant tissue have been associated with subsequent disease $(1,17,23,24,27)$, most studies have not enabled a quantitative relationship to be determined between population sizes on individual plant parts and subsequent disease. However, pioneering studies of $P$. syringae revealed that assessments of the probability distribution of bacterial populations on individual leaves could allow estimations of the frequency with which a given bacterial population size is met or exceeded (22). When coupled with estimates of the probability of disease given a particular bacterial population size, the incidence of brown spot disease of bean could be predicted up to 11 days later from measurements of $P$. syringae population sizes on individual leaves (22). In a similar strategy, incidence of pear bud failure caused by $P$. syringae could be predicted from prior measurements of mean log population sizes of this pathogen (17). The results of this study suggest that disease risk forecasts based on $X$. arboricola pv. juglandis populations in buds offers the potential to anticipate disease of nuts several weeks in advance of infection.

\section{ACKNOWLEDGMENTS}

We thank M. Hendson, A. Haxo, H. Gao, S. Kauer, L.-M. Gong, and R. Koutsoukis for assistance in assessing $X$. arboricola pv. juglandis population sizes and other technical assistance; and S. Sibbett, L. Hendricks, B. Beede, J. Grant, B. Teviotdale, and J. Hassey (University of California Cooperative Extension) for assistance in establishing and sampling field experimental sites.

\section{LITERATURE CITED}

1. Bedford, K. E., MacNeill, B. H., Bonn, W. G., and Dirks, V. A. 1987. Population dynamics of Pseudomonas syringae pv. papulans on Mutsu apple. Can. J. Plant Pathol. 10:23-29.

2. Belisario, A., Zoina, A., Pezza, L., and Luongo, L. 1999. Susceptibility of species of Juglans to pathovars of Xanthomonas campestris. Eur. J. For. Pathol. 29:75-80.

3. Buchner, R. P., Adaskaveg, J. E., Olson, W. H., and Lindow, S. E. 2001. Walnut blight (Xanthomonas campestris pv. juglandis) control investigations in northern California, USA. Acta Hortic. 544:369-378.

4. Buchner, R. P., Gilles, C., Olson, W. H., Adaskaveg, J. E., Lindow, S. E., and Koutsoukis, R. 2010. Spray timing and materials for walnut blight (Xanthomonas campestris pv. juglandis, Xanthomonas arboricola pv. juglandis) control in Northern California USA. Acta Hortic. 861:457-464.

5. Esterio, M. A., and Latorre, B. A. 1982. Potential sources of inoculum of Xanthomonas juglandis in walnut blight outbreaks. J. Hortic. Sci. 57:69-72.

6. Frutos, D. 2010. Bacterial diseases of walnut and hazelnut and genetic resources. J. Plant Pathol. 92:S1.79-S1.85.

7. Gonzales-Barron, U., Kerr, M., Sheridan, J. J., and Butler, F. 2010. Count data distributions and their zero-modified equivalents as a framework for modelling microbial data with a relatively high occurrence of zero counts. Int. J. Food Microbiol. 136:268-277.

8. Hirano, S. S., Nordheim, E. V., Arney, D. C., and Upper, C. D. 1982. Lognormal distribution of epiphytic bacterial populations on leaf surfaces. Appl. Environ. Microbiol. 44:695-700.

9. Hirano, S. S., and Upper, C. D. 2000. Bacteria in the leaf ecosystem with emphasis on Pseudomonas syringae - a pathogen, ice nucleus, and epiphyte. Microbiol. Mol. Biol. Rev. 64:624-653.

10. Johnson, K. B., Stockwell, V. O., McLaughlin, R. J., Sugar, D., Loper, J. L., and Roberts, R. G. 1993. Effect of antagonistic bacteria on establishment of honey bee-dispersed Erwinia amylovora in pear blossoms and on fire blight control. Phytopathology 83:995-1002.

11. King, E. O., Ward, M. K., and Rainey, D. E. 1954. Two simple media for the demonstration of pyocyanin and fluorescein. J. Lab. Clin. Med. 44:310-307.

12. Lang, M. D., and Evans, K. J. 2010. Epidemiology and status of walnut blight in Australia. J. Plant Pathol. 92:S1.49-S1.55.

13. Lee, Y.-A., Hildebrand, D. C., and Schrost, M. N. 1992. Use of quinate metabolism as a phenotypic property to identify members of Xanthomonas campestris DNA homology group 6. Phytopathology 82:971-973.

14. Lindow, S. E., and Brandl, M. T. 2003. Microbiology of the phyllosphere. Appl. Environ. Microbiol. 69:1875-1883.

15. Lindow, S. E., and Leveau, J. H. J. 2002. Phyllosphere microbiology. Curr. Opin. Biotechnol. 13:238-243.

16. McGuire, R. G., Jones, J. B., and Sasser, M. 1986. Tween media for semiselective isolation of Xanthomonas campestris pv. vesicatoria from soil and plant material. Plant Dis. 70:887-891.

17. Montesinos, E., and Vilardell, P. 1991. Relationships among population levels of Pseudomonas syringae, amount of ice nuclei, and incidence of blast of dormant flower buds in commercial pear orchards in Catalunya, Spain. Phytopathology 81:113-119.

18. Mulrean, E. N., and Schroth, M. N. 1982. Ecology of Xanthomonas campestris pv. juglandis on Persian (English) walnuts. Phytopathology 72:434-438.

19. Ninot, A., Aleta, N., and Montesinos, E. 2002. Evaluation of a reduced copper spraying program to control bacterial blight of walnut. Plant Dis. 86:583-587.

20. Olson, W. H., Buchner, R. P., Adaskaveg, J. E., and Lindow, S. E., 1997. Walnut blight control in California. Acta Hortic. 442:361-366.

21. Olson, W. H., Moller, W. J., Fitch, L. B., and Jeter, R. B. 1976. Walnut blight control. Calif. Agric. 30:10-13.

22. Rouse, D. I., Nordheim, E. V., Hirano, S. S., and Upper, C. D. 1985. A model relating the probability of foliar disease incidence to the population frequencies of bacterial plant pathogens. Phytopathology 75:505-509.

23. Smitley, D. R., and McCarter, S. M. 1982. Spread of Pseudomonas syringae pv. tomato and role of epiphytic populations and environmental conditions in disease development. Plant Dis. 66:713-717.

24. Thompson, S. V., Schroth, M. N., Moller, W. J., and Reil, W. O. 1975. Occurrence of fire blight of pears in relation to weather and epiphytic populations of Erwinia amylovora. Phytopathology 65:353-358.

25. Upper, C. D., Hirano, S. S., Dodd, K. K., and Clayton, M. K. 2003. Factors that affect spread of Pseudomonas syringae in the phyllopshere. Phytopathology 93:1082-1092.

26. Vagelas, L. K., Rumbos, C. I., Tsiantos, J., Janse, J. D., Pulawska, J., Scortichini, M., Duffy, B., and Edizioni, E. T. S. 2012. Variation in disease development among Persian walnut cultivars, selections and crosses when inoculated with Xanthomonas arboricola pv. juglandis in Greece. J. Plant Pathol. 94:S1.57-S1.61.

27. Weller, D. M., and Saettler, A. W. 1980. Colonization and distribution of Xanthomonas phaseoli and Xanthomonas phaseoli var. fuscans in fieldgrown navy beans. Phytopathology 70:500-506.

28. Woeste, K. E., McGranahan, G. H., and Schroth, M. N. 1992. Variation among Persian walnuts in response to inoculation with Xanthomonas campestris pv. juglandis. J. Am. Soc. Hortic. Sci. 117:527-531. 